\title{
GIS-HBIM INTEGRATION FOR THE MANAGEMENT OF HISTORICAL BUILDINGS
}

\author{
Giuseppina Vacca ${ }^{1}$, Emanuela Quaquero ${ }^{1}$, Davide Pili ${ }^{1}$, Mauro Brandolini ${ }^{1}$ \\ ${ }^{1}$ Dept. of Civil Engineering, Environmental and Architecture, University of Cagliari (CA), Italy.
}

Commission II, WG II/8

KEY WORDS: HBIM, GIS, management strategies, heritage

\begin{abstract}
:
As is well known, Italy's very consistent buildings stock has become the major field for real estate investments and for the related projects and actions. It is a heritage that is often barely known and extremely complex, whose management has until now been addressed in a rather casual and uninformed manner, with unsatisfactory and sometimes disastrous outcomes. The situation is worse in the case of buildings of particular historical, artistic and architectural value so frequent within the heritage of our country.

This paper shows the findings of an ongoing research which is aimed at structuring the cognitive process and assessing enhancement and re-functionalisation scenarios of our historical and architectural heritage through the use and integration of information systems such as BIM and the GIS. The work led to the development of a workflow able to integrate the contribution of the HBIM and GIS methodologies in the structuring and management of a wide range of digital data and information useful for its management. The research, focused on "La Gran Torre di Oristano, is aimed at creating the best conditions for an integrated and multidisciplinary strategy of requalification and refunctionalisation of historical and architectural heritage.
\end{abstract}

\section{INTRODUCTION}

Italy's very consistent buildings stock has become the major field for real estate investments and for the related projects and actions. It is a heritage that is often barely known and, in any case, extremely complex and diversified, whose recovery and management has until now been addressed in a rather casual and uninformed manner, with unsatisfactory and sometimes disastrous outcomes.

The lack of "As Built" documentation (building components, installations, etc.) and the complex task of detecting their current status in terms of use (intended use and space dimensions, environmental context, etc.) and maintenance (conservation status of building components, age of the technological installations, previous maintenance work, compliance with current regulations, etc.) causes deep difficulties in planning, scheduling and controlling appropriate interventions. The situation is worse in the case of buildings of particular historical, artistic and architectural value so frequent within the heritage of our country.

Thus, in order to accomplish their duties, the agencies appointed with managing and maintaining these buildings need a great amount of information coming from several sources. These are historical documents, design plans, historical-structural investigations, geomatic and photographic surveys. As of today, all of this documentation is of a $2 \mathrm{D}$ nature and contains only geometry data, without concern for semantics or relationships between the objects that form the building. The ability to describe the building in detail and in three or four dimensions (including changes in time) would be a remarkable benefit. This can be done by using Building Information Modelling (BIM), which is already used in new buildings ("as-designed BIM"), but with the use of modern geomatic acquisition techniques such as digital multi-image photogrammetry or terrestrial laser scanning (TLS), can also be used in modelling existing buildings ("as- built BIM"). (Pavel, 2016)

In this regard, the contribution of Historical Building Information Modelling/Management (HBIM) is considered strategic (Yang 2016). The added value of HBIM tools and methods consists not only in the extreme ease of creating three-dimensional views of the modelled building, but also in the possibility of implementing 3D models with information relevant for the management of the specific building and its components. In addition to the BIM technology, in the recent years the GIS (Geographic Information Systems) are proving to be of great help in the management of the historical heritage. Although they were originally developed to manage vast territories in a $2 \mathrm{D}$ format, they provide a robust data storage system, definition of topological and semantic relationships, and spatial queries, which make them suitable tools for the management of historical buildings (Rinaudo 2007). In particular, this adaptation was made possible by the development of 3D GIS. These GIS methodologies have allowed a management of data and precise information of the specific building and also an accurate understanding of the relative urban, historical and geographical contextualisation. Although these tools are widespread in the administrations which are responsible for managing this enormous heritage, there is still a lack in the process of visualization and interpretation of the specific building and its components. This fact negatively influences intervention decisions.

The BIM-GIS integration is a strong support for designing a smart sustainable city, due to its capabilities in data integration, quantitative analysis, application of technologies and urban management (Ma, et al., 2017), (Fosu, et al., 2015), (Yamamura, et al., 2016), (Ding, et al., 2017).

BIM has advantages on rich geometric and semantic information through the building life cycle (Volk, et al., 2017), while GIS is a broad field covering geovisualisation-based decision making and geospatial modelling (Berry, 1996).

This paper shows the findings of an ongoing research which is aimed at structuring the cognitive process and assessing enhancement and re-functionalisation scenarios of our historical and architectural heritage.

The research, focused on "la Gran Torre di Oristano", an important asset of the Sardinian coast located in one of the most important territorial contexts of the region both from the point of view of tourism and from the historical-archaeological point of view. The work led to the development of a HBIM-GIS workflow 
able to formalize the cognitive process of a historical building, according to its management.

The first part of the article concerns the transition from traditional methods to BIM / HBIM and to the problems of HBIM/GIS integration, its potential, and to future developments. The second part presents the case study developed on the Gran Torre (Great Tower) of Oristano, a historic building of considerable importance in Sardinia (Italy), dating to the mid-1500s; a 3D model of the tower was created within the Revit software (Autodesk) and subsequently integrated into a 3D GIS created with the ArcGIS software.

This research is part of the Italian research project called "Tecniche murarie tradizionali: conoscenza per la conservazione ed il miglioramento prestazionale" (Traditional building techniques: from knowledge to conservation and performance improvement), which aims to survey, date, and characterize in technical and energy performance terms the construction techniques of the historical architecture in Sardinia between the 13th-19th century. The research project has a time span of three years, and will conclude in September 2018.

\section{INTEGRATION HBIM-GIS}

\subsection{From traditional methods to the BIM}

The definition of BIM that best describes the real essence of the method is certainly the one in Eastman: "BIM is not a thing or a software, but a human activity that involves ultimately a vast change in the processes of the building industry." (Eastman, 2001) BIM must then be intended as a paradigm change in the management of the building process, in which integration and systemic approach become essential.

The BIM methodology is nothing more than an advanced system of management of the building process in which accurate virtual models represent the instrument on which all phases of the building life cycle are based, obtaining the maximization of the efficiency of the processes and the quality of the results.

Operating in a BIM environment means creating the parametric model of a building, able to simulate and respect the actual relationships between its constituent parts.

The model is fundamental both during the design and building phases, and for the management and maintenance of the completed building, until the end of its life cycle.

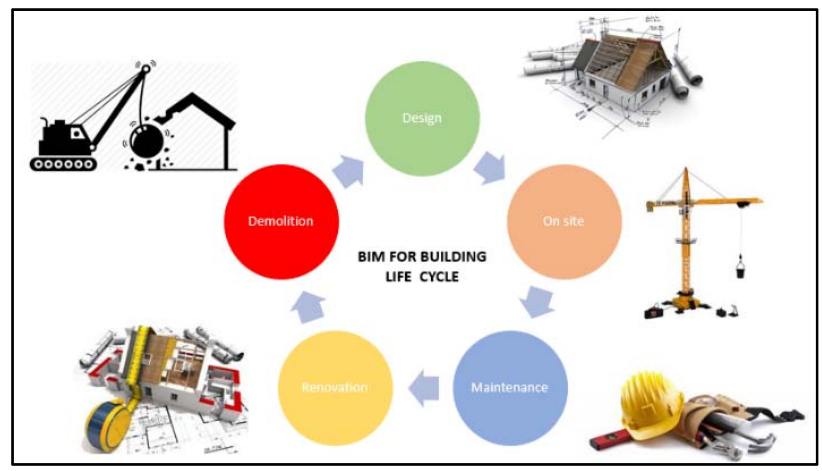

Figure 1. BIM and Building life cycle

In Italy, BIM has been spreading in the field of design for a few years, and designers are showing more and more interest, also taking advantage of the necessary improvements to the organizational system that the design structure must take on. However, if we consider the effort that must be implemented within the entire life cycle (going from the planning phase to the building management phase), even considering the intrinsic advantages of a BIM design, we must note that the phases of design, choice of contractor and execution have a very limited duration over time compared to the management phase of the building. In fact, the management phase occupies a substantial portion of the life cycle of the building, a phase that is spread over a much longer period of time and with subsequent costs, which, although diluted over time, present a value that is clearly superior to those in the design and construction phases. To prove this, many studies report the following data: about $60 \%$ of the advantages related to the use of BIM concern the management phase, $30 \%$ the construction phase and the remaining $10 \%$ the design phases. (Di Giuda, 2017)

The benefit of using BIM software consists, besides the ease in producing axonometric and perspective views of the modeled asset, in complementing the 3D model with all the information that is deemed relevant for the knowledge and management of the building. The models such built are ready for visualization, navigation, and analysis through a process of selection of their component elements.

Differently from what happens in a traditional CAD software, where there is no digital relationship between different products (which often end up being inconsistent with each other), a BIM stores all data in a single database, which is then used to produce the blueprints, spreadsheets, and $2 \mathrm{D}$ and $3 \mathrm{D}$ views. In this way the system, based on a parametric model, coordinates and updates automatically all modifications, ensuring the consistency of the information in all the different architectural outputs. Considering that the parametric model is created by integrating virtual elements that simulate the construction elements of the building, it is necessary to perform some preparatory actions before putting the model together. First, we must classify and organize the construction elements into semantic categories ("families"), define the choice of contents we want to represent, and by consequence, the level of detail (LOD) of the model. This premodeling phase is of paramount importance, as it determines the degree of precision needed to fulfill our objectives.

Using a BIM for an already constructed building is surely more complex, but there are several studies and research about this approach, especially in the case of buildings of historical and architectural relevance.

In the transition from BIM to HBIM, the informative modeling of historical architecture need a particular consideration.

Compared to a new building, it often has geometric and dimensional features that are difficult to combine with modeling from standardized objects. In fact, the complex elements characterizing historic buildings imply a rather difficult threedimensional parametric restitution. Even if parametric software allows us to model virtually any shape, in the face of complex elements (such as those deriving from the restitution of historic buildings), a considerable amount of time is required, so that each time the actual cost- benefits balance of a modeling carried to the extreme detail needs to be assessed. Also, we must take into due consideration the fact that, at present, even exploiting sophisticated laser scanning technologies, the result obtained would always have a certain degree of approximation (Osello 2015). From what has been said, one can easily understand that the theme of defining the Level of Detail (LOD) of the model, in the case of historic buildings, is of utmost importance, and far more complex to manage than in the case of new buildings. These problems are then compounded by the wide range of heterogeneous information concerning the former. Current state of conservation, materials, techniques and construction technologies used, conditions of deterioration, restoration interventions carried out, treatments carried out, simulations of 
new interventions, etc., represent the wide range of data that the HBIM information model has to structure and handle.

In (Foxe, 2010) the author notes that in the case of an existing building its model is always to a certain extent different from the actual object. There is always a certain level of simplification and abstraction and too much detail can also be inappropriate considering the increasing amounts of data which must be processed during further work with the model. Moreover, it is worth mentioning that the level of detail does not only apply to geometry but it is also related to the accuracy of attributes descriptive information. In this context, the term "level of development" is more suitable.

More generally, we can say that a HBIM should always include the following data or information (Pavel, 2016):

1. Building location and identification in the national datum

2. Historical documents

3. Architectural analysis of the building (materials, construction systems, etc.)

4. Information about the condition of the building

5. Information about reconstructions, maintenance and other interventions

\subsection{HBIM and GIS for management strategies of} architectural and historical heritage

As previously said, the strength of a Historcal BIM lies in creating 3D models using parametric elements taken from common libraries that are suitable for all buidings; what is still a problem is the construction of complex 3D spatial queries, and the integration of the 3D model in its surroundings (and possibly in an urban model). This fact does not allow to plan for the interventions taking into account also information concerning the specific context. GIS, however, is able to represent the environment and all the information related to it, besides building those complex and spatial queries that are not possible within the HBIM.

Several works have evidenced the importance of integrating HBIM and GIS, such as (Isikdag, 2008) noting that an implementation of BIM in the geospatial context can be useful for site selection analyses, simulations to determine energy consumption and lighting requirements in buildings, fire response management operations and $\mathrm{N}$-dimensional analyses at the urban level. (Donkers, 2013) states that such integration can also be useful for cadastral uses, environmental analysis, architectural uses, or for real estate agents.

Still, in the real world the integration of the two systems still presents several obstacles such as the different ways of representing geometries, the use of different datums and coordinate systems, and the different semantics used. The effort of the researchers in this field is directed towards solving these problems.

The presented work is specifically focused on the construction of a platform able to integrate the contribution of the HBIM and GIS methodologies, in the structuring and management of a wide range of digital data and information about the status of the Gran Torre.

\section{THE CASE STUDY: THE GRAN TORRE OF ORISTANO (SARDINIA)}

\subsection{The Gran Torre of Oristano}

Built in the second half of the 1500s, the Gran Torre (Figures 1 and 2) is a great "torre de armas", on the coast of the homonymous locality, intended for heavy defense. It is the largest construction of the entire coastal defense system of
Sardinia and it communicates visually with the adjacent towers of Capo Frasca, Marceddì, Cabras, Capo San Marco and San Giovanni di Sinis. It was built by the Spanish Viceroy Carlo V (1537); initially it was called "Torre del puerto de Oristan" (1639) and only in the Savoy age it assumed its current name. Although started in the first half of the 16th century, the tower is of Aragonese conception, as evidenced by the characteristics of architecture. Currently the Gran Torre presents itself as a massive cylindrical body of about $19 \mathrm{~m}$ in height and $21 \mathrm{~m}$ in diameter (Figures 2 and 3).

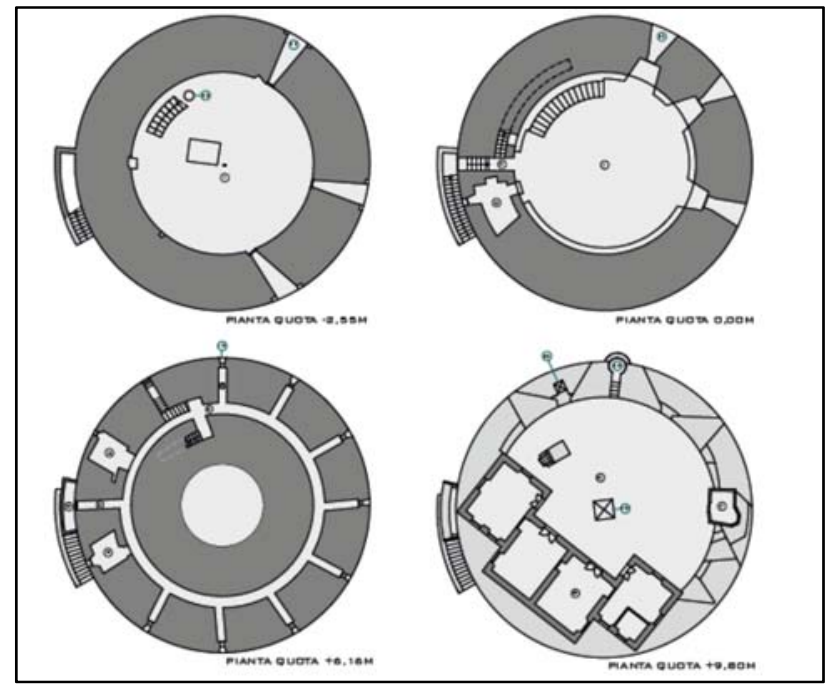

Figure 2. The Gran Torre of Oristano - plans

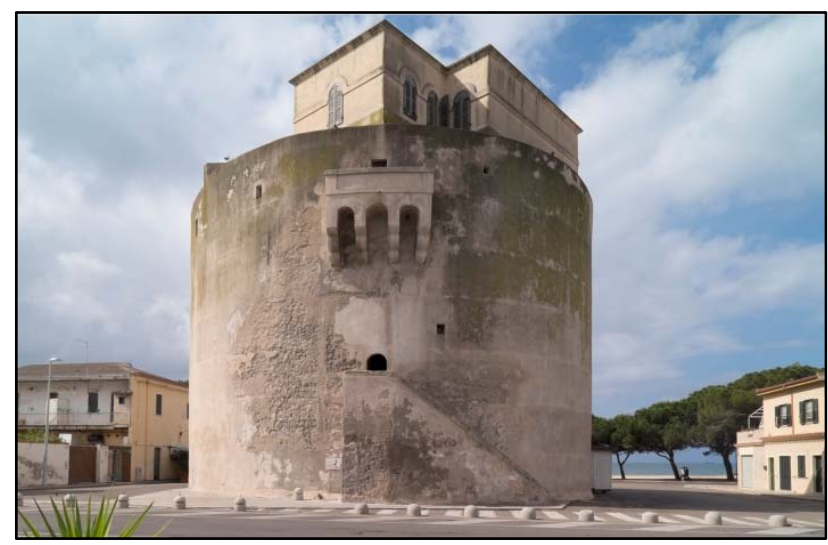

Figure 3. The Gran Torre of Oristano

An external staircase, made of masonry, allows access to the north-east of the building at a height of $3.70 \mathrm{~m}$. By means of another small ramp, a further difference in height of about $1 \mathrm{~m}$ is overcome, thus reaching a large room, 13 meters in diameter, which constitutes the main room. Adjacent to the entrance there is a small room built into the wall thickness, covered by a barrel vault and equipped with a slit to protect the access ladder. The main compartment is delimited at the bottom by a wooden deck built during the last restoration, in order to allow the use of the environments discovered as a result of these excavations. It has an imposing domed roof, with a quadrangular central opening, while on the outer walls there are three gunboats. From the main room it is possible to access the stairwell, also built in the wall thickness. This vertical connection leads to a height of $6.16 \mathrm{~m}$ 
where there is a vaulted corridor, built between the extrados of the vault and the tower wall.

The parade ground can be reached through another small flight of stairs cut into the thickness of the wall. The parade ground hosts the traffic light system and a building with a ' $U$ ' plan, divided into four symmetrical rooms. A steel and wood staircase, recently inserted, allows access to the sub-floor, at $-2.55 \mathrm{~m}$.

Currently, the tower is in a discrete, but not optimal, state of conservation. In particular, while the wall system and the vaulted structures have a good structural efficiency, the plastered surfaces present different pathologies due to the use of unsuitable materials during the most recent restoration interventions. In addition, the paving of the parade ground has widespread lesions and local disconnections caused by the abundant presence of infesting vegetation.

\subsection{The information model of the Gran Torre of Oristano}

Starting from the careful analysis of the propriety information, we proceeded with the selection of the subject for the parametric modelling. The BIM model, in fact, does not represent the universal container for every type of information, but must be conceived within a specific and focused programme. the work continued with the definition of a conceptual scheme for the decomposition of the building in categories of constructive objects (PBS), with the choice of alphanumeric content to be capitalised for each one of them and, therefore, with the definition of the detail level of the model. Finally, we selected a set of parameters required to "inform" the components of the model. In particular, the parameters were defined to capitalize the construction techniques used, the prevailing materials, the state of degradation, the type of degradation and the degree of transformability.

Starting from the 2D survey, archived at the offices of the Archaeological Superintendence, Fine Arts and Landscape for the Province of Oristano, we proceeded by developing the parametric model with the BIM Autodesk Revit software.

This phase highlighted the complexity of application of the logic of the software itself, created for the modeling of new construction interventions and not for the representation of a historic building.

For the construction of elements such as walls, floors and flat roofs, it was sufficient to use 'system families', which constitute the main structure of the model. The windows were created using "loadable families"; they are created in external RFA files and imported into the project. The most complex part of the modeling of the Gran Torre was the realization of particular elements typical of the building, such as the vaulted roofs, the external staircase, the splayed gunboats, the internal staircase, the balcony, the geodesic point and the watchtower. These constructive elements were modeled through the use of 'in place families'. Local families can be created in the current project but they have the disadvantage of not being able to be used in other projects, and their repeated use also makes the model file heavy. We reproduced the particular shapes of the components of the building within the modelling frame, by using commands such as extrude, join and revolve. A different work was done for the construction of the external staircase and the intramural internal staircase. In these elements the masonry surfaces and intramural voids follow the inclined path of the stairs. This fact makes it impossible to use 'in place families'. Therefore, for the realization of these elements, it has become essential to use the 'local masses' tool.

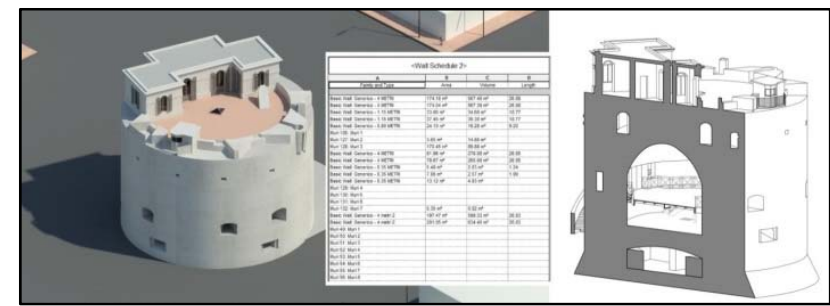

Figure 4. The informative model HBIM developed in Revit

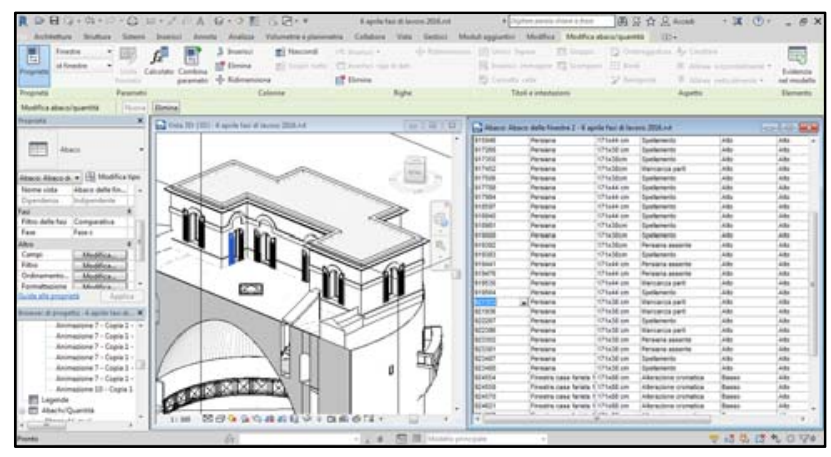

Figure 5. Objects, data and information in Revit

\section{WORKFLOW HBIM-GIS}

\subsection{From HBIM to GIS 3D}

The aim of this experimentation was to create a working HBIMGIS protocol, with the purpose of digitizing and optimizing the processes of accurate surveying aimed at the correct management of the historical architectural heritage through the modern IT tools of HBIM and 3D GIS.

The GIS software used is ArcGIS 10.6 by Esri. In order to import the data into ArcGIS we developed a workflow that, through several complex passages, allowed us to integrate the 3D model of the "Gran Torre" into ArcGIS and ArcScene.

Based on the information model built in Revit, as described above in Par. 3.2, the first step in the workflow is exporting the spreadsheets created inside Revit in text format. Then after loading in Revit the "FME Exporter for Revit" plugin, the entire model was exported into the .rvz format, but not before setting the correct latitude and longitude in the ETRF2000 official datum (Barbarella, 2014). The .rvz file thus created was verified with the "FME Inspector" application in order to ensure that all the structured information from Revit was correctly exported. After verifying the .rvz file, the same was opened in the "FME Workspace" application and then converted into a .gdb (geodatabase) file, in order to manage the model and related information in ArcGIS. 


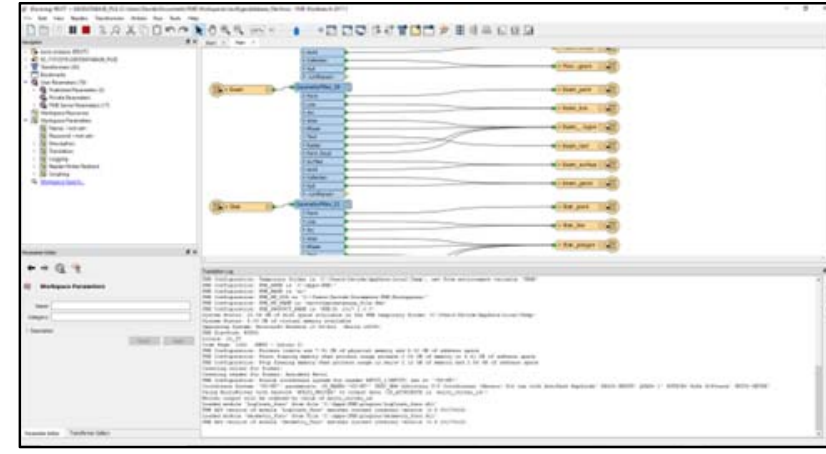

Figure 6. FME workspace

After importing the .gdb file in ArcScene, it was possible to navigate the 3D model of the "Gran Torre", placed within its urban context. Insite ArcScene it was possible to execute complex queries, which could not be performed inside Revit. Such queries are of great importance, especially in the management and maintenance phases of the building's life cycle, as they give the ability to rationally structure the interventions for the restoration, repurposing and maintenance of the building. Figures 6, 7 and 8 report, as an example, the selection of the fixtures of the residence of the lighthouse keeper inside ArcScene. Among those same fixtures, the ones with both high degradation and high transformability level were selected. The transformability level is the highest allowed level of intervention allowed on an element, considering his historical, architectural and technical value. The higher the values that must be preserved, the lower is the transformability level. We thus selected those components of the residence that would be targeted in a restoration intervention, as they were both in need of maintenance and not needing to be preserved.

The ability to identify on the parametric model and on the related urban context (figures 10,11 ) the components that primarily need intervention allows us to consider and evaluate the important logistical and operative aspects of the intervention, also optimizing the management of safety measures in the restoration work environment (with a correct choice of the machinery, tools, temporary works and procedures to be employed).

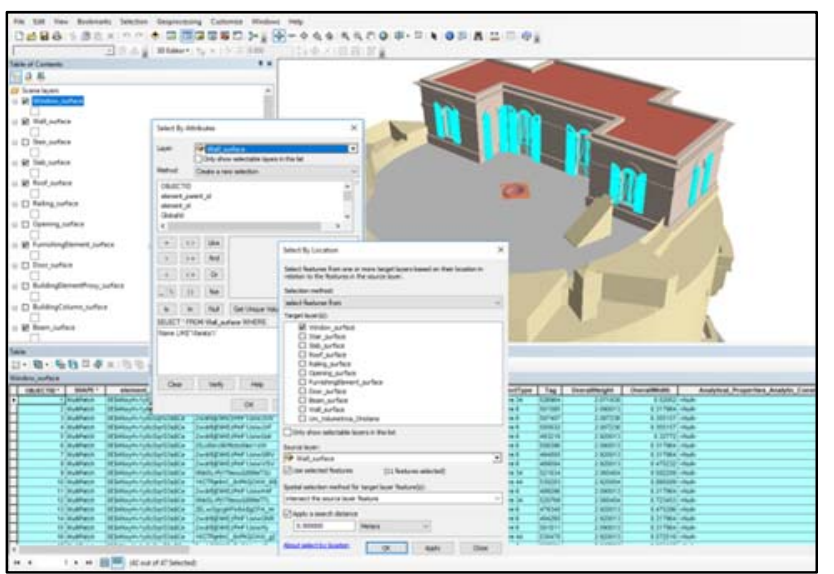

Figure 7. Selection of the windows in the residence of the lighthouse keeper in Arcscene

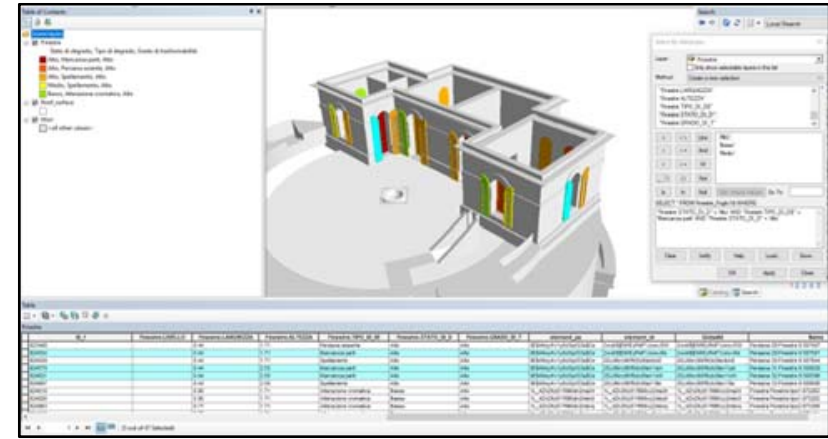

Figure 8. Selection of the windows with high degradation level in Arcscene

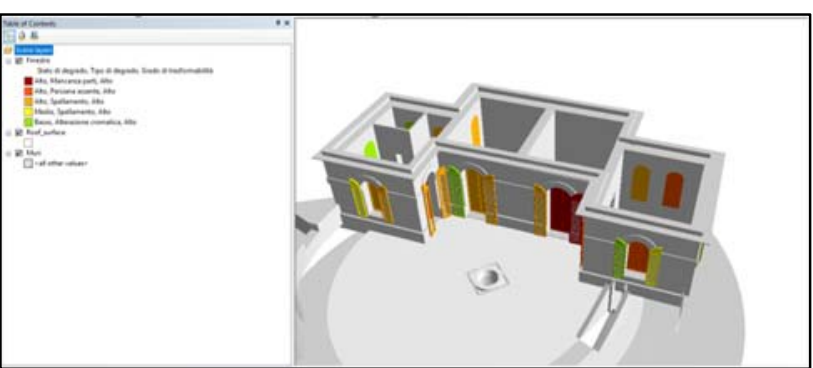

Figure 9. Selection of the windows with high transformability level in Arcscene

As for the potential of HBIM-GIS integration, the parametric model of the Gran Torre has been inserted into the 3D model of the city in which it is located. The cartographic base used is the orthophoto with GSD of $20 \mathrm{~cm}$ of the Sardinia Region (WebGIS Regione Sardegna 2013), while the GIS 3D was built from the "Unità Volumetrica" (Buildong-Volume Unit) class of the geodatabase of the Sardinia region (WebGIS Regione Sardegna, 2013). The features in this class represent a part of a building having constant ground and a top altitude, and are polygon primitives with "ground altitude" and "top altitude" attributes. Using this information, it is possible to extrude the polygons into 3D models of the architectural units. (Vacca et al., 2018; Deidda et al., 2013).

Through these operations it was possible to insert the 3D model of the Gran Torre within a 3D model of the simplified city, providing the opportunity to perform spatial analysis within the city (disaster management, training simulator, visualization purposes).

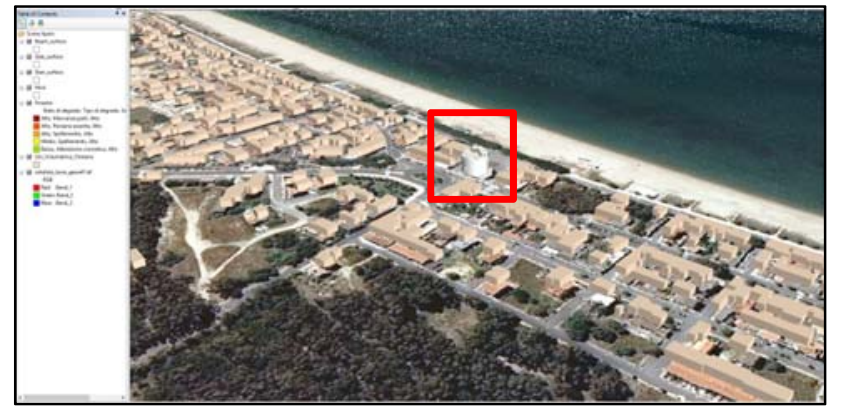

Figure 10. The parametric model in the urban context 


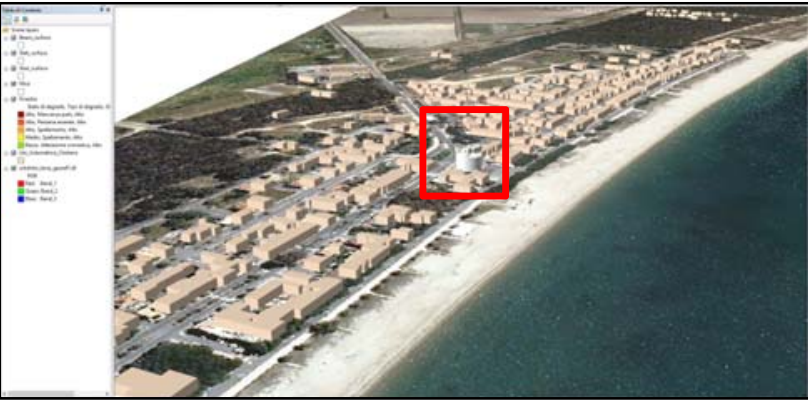

Figure 11. The parametric model in the urban context

\section{CONCLUSIONS AND FUTURE DEVELOPMENTS}

The experimentation illustrated in the present contribution allowed to arrive at some considerations about the results obtained and the possible implementations of the research.

The most important result is the awareness of the need to reason in terms of interoperability: starting from the identification of the physiological limits of each ICT, we worked on the structuring of communication and relationship interfaces between GIS and HBIM. From the experimentation carried out it emerges that the integrated HBIM-GIS system is configured as a viable and sustainable solution for a better understanding of the historical architectural artefact and for an efficient management of the design and executive phases in the conservative process. All this provided that the objectives of the work are adequately identified and an adequate selection of the necessary information has been carried out, as well as the introduction of reporting parameters on which a possible comparative analysis can be carried out.

According to this approach, the restoration project is configured as the result of appropriately "informed", rational and conscious choices. The intervention is the result of the various specialist contributions involved that intervene from the beginning of the process in a coordinated manner.

Future developments include the possibility of gradually replacing the commercial applications used in this experiment with open source applications.

\section{Acknowledgments}

The research "Tecniche murarie tradizionali: conoscenza per la conservazione ed il miglioramento prestazionale" was financed by the Autonomous Sardinia Region within the "L. R. n. 7/2007 Promozione della ricerca Scientifica e dell'innovazione tecnologica in Sardegna" (Regional Law 7/2007-Promotion of scientific research and technological innovation in Sardinia). Principal Investigator C. Giannattasio, Reasearch Unit 1, Scientific coordinator for GIS and WebGIS G. Vacca, Scientific coordinator for BIM and HBIM E. Quaquero, working Group from the University of Cagliari, Department of Civil, Environmental Engineering and Architecture (DICAAR).

\section{REFERENCES}

Barbarella, M. 2014. Digital technology and geodetic infrastructures in Italian cartography. Citta' e Storia 2014, 9, 91110).

Berry, J. 1996. GIS evolution and future trends. In Beyond Mapping III, Compilation of Beyond Mapping Columns Appearing in GeoWorld Magazine; BASIS Press: Quincy, MA, USA.
Deidda, M.; Pala, A.; Vacca, G., 2013. An example of a tourist location-based service (LBS) with open-source software. Applied Geomatic, 5, pp.73-86.

Deidda, M.; Musa, C.; Vacca, G., 2015. A GIS of Sardinia's Coastal defense system (XVI-XVIII century). Int. Arch. Photogramm. Remote Sens. Spat. Inf. Sci., 40-4/W7, pp.17-22.

Di Giuda G.M., Maltese S., Re Cecconi F., Villa V., 2017.“Il BIM per la gestione dei patrimoni immobiliari. Linee guida, livelli di dettaglio informativo grafico (LOD) e alfanumerico (LOI)". Milano. Hoepli.

Ding, L., Fiorito, F., Osmond, P. 2017. Eds.; Procedia Engeenering; Elsevier Science BV: Amsterdam, The Netherlands, 2017; Volume 180, pp. 1462-1472.

Donkers, D. 2013. "Automatic generation of CityGML LoD3 building models from IFC models:" $\mathrm{PhD}$ thesis. Delft University of Technology, 2013. url:http://oatd.org/oatd/record?record=oai\%5C:tudelft.nl\%5C:u uid\%5C:31380219- f8e8- 4c66- a2dc-548c3680bb8d

Eastman, C., Teicholz, P., Sacks, R. and Liston K. 2011. BIM Handbook: A Guide to Building Information Modeling for Owners, Managers, Designers, Engineers and Contractors, Hoboken: John Wiley and son, Inc.

Fosu, R.; Suprabhas, K.; Rathore, Z.; Cory, C. 2015. Integration of Building Information Modeling (BIM) and Geographic Information Systems (GIS)-A literature review and future needs. In Proceedings of the 32nd CIB W78 Conference, Eindhoven, The Netherlands, 27-29 October 2015.

Foxe, D. M. 2010. "Building Information Modeling for Constructing the Past and Its Future". English. In: APT Bulletin 41.4 (Jan. 2010), pp. 39-45. issn: 0848-8525. url: http://www.jstor.org/stable/41000037

Isikdag, U., Underwood, J. and Aouad, G. 2008. "An investigation into the applicability of building information models in geospatial environment in support of site selection and fire response management processes". In: Advanced Engineering Informatics 22.4 (2008), pp. 504-519. doi: 10.1016/j.aei.2008.06.001.

Ma, Z.; Ren, Y. 2017. Integrated Application of BIM and GIS: An Overview. Procedia Eng., 196, 1072-1079.

Osello, A. 2015. Building Information Modelling, Gegraphic Information System, Augmented Reality per il Facility Management. Palermo: Dario Flaccovio editore.

Pavel, T. (2016). BIM, GIS and semantic models of cultural heritage buildings. Geoinformatics FCE CTU. 15. 27. 10.14311/gi.15.2.3.

Rinaudo, F.; Agosto, E.; Ardissone, P. 2007. GIS and Web-GIS, commercial and open source platforms: general rules for cultural heritage documentation. International archives of the photogrammetry, remote sensing and spatial information sciences 2007, Volume XXXVI-5/C53, pp. 625-630.

Vacca, G.; Fiorino, D.R.; Pili, D. 2018. A Spatial Information System (SIS) for the Architectural and Cultural Heritage of Sardinia (Italy). ISPRS Int. J. Geo-Inf. 2018, 7, 49. 
Volk, R.; Stengel, J.; Schultmann, F. 2014. Building Information Modeling (BIM) for existing buildings-Literature review and future needs. Autom. Constr. 2014, 38, 109-127.

Yamamura, S.; Fan, L.; Suzuki, Y. 2016. Assessment of Urban Energy Performance through Integration of BIM and GIS for Smart City Planning. In International High-Performance Built Environment Conference-A Sustainable Built Environment Conference 2016 Series (SBE16), IHBE 2016;

Yang, X.; Koehl, M.; Grussenmeyer, P.; Macher, H. 2016 Complementary of historic building information modelling and Geographic Information Systems. International archives of the photogrammetry, remote sensing and spatial information sciences 2016, Volume XLI-B5, pp. 437-443. 